\title{
Glass Transition Temperature Profile of the Curing Reaction of Unsaturated Polyester Resin
}

\author{
Tzyy Lung Yu
}

\author{
Department of Chemical Engineering, Yuan-Ze Institute of Technology, \\ Nei-Li, Taoyuan, Taiwan 32026, Republic of China
}

(Received April 3, 1996)

\begin{abstract}
The curing reaction of unsaturated polyester/styrene system was investigated by differential scanning calorimetry (DSC). Between gelation and vitrification (where $T_{\mathrm{g}}$ of the curing system equals to the curing temperature), the propagation of the curing reaction is kinetically controlled whilst the termination reaction is diffusion controlled. After vitrification, both the propagation and termination reactions are diffusion controlled. The variation of $T_{\mathrm{g}}$ during the curing reaction was calculated from the curing profile obtained from DSC measurements by using an empirical equation developed in a previous work. The experimental data indicated that there exist a critical point such that the time-temperature shifts of $T_{\mathrm{g}}$ vs. $\ln$ (cure time) data at different cure temperatures formed a master curve between critical point and vitrification at an arbitrary reference temperature and yielded a single Arrhenius activation energy. These results indicated that polymerization between critical point and vitrification was $T_{\mathrm{g}}$ dependent only.

KEY WORDS Unsaturated Polyester / Glass Transition Temperature / Differential Scanning Calorimetry /
\end{abstract}

Unsaturated polyester resin is one of the most important thermosetting resins for preparing molding compounds (SMC and BMC), resin transfer molding (RTM), hand lay up fiber reinforced plastics, and filament winding fiber reinforced plastics, etc. ${ }^{1,2}$ Recently, the processing of thermosetting unsaturated polyester resins has received increasing attention from industry, especially from the automotives and aerospace industries.

Curing of unsaturated polyester resins generally involves the transformation of low molecular weight amorphous solids by means of chemical reactions. The curing process is of particular importance in the making of structural composites, coatings, adhesives, and electronic encapsulants. An useful framework for understanding and conceptualizing the changes that occur during cure of a thermostting system is the isothermal time-temperature-transformation curves. ${ }^{3}$

The curing of styrene-unsaturated polyester resins is a free radical polymerization. The reaction of styrene with unsaturated polyester includes not only kinetic reaction but also gelation and network formation. Several researchers ${ }^{4,5}$ reported that before gelation "microgel" structure formed through intra-molecular cross-linking among the pendant $\mathrm{C}=\mathrm{C}$ bonds of the polyester molecule. As the polymerization proceeds, the microgel particles growth both in particle sizes and numbers and the system gelled at a critical conversion where the microgel particles started to overlap. After gelation the termination between the free radical polymer chains becomes diffusion controlled, the rate coefficient for termination begins to decrease markedly and the reaction rate increases rapidly. During curing the glass transition temperature $\left(T_{\mathrm{g}}\right)$ of the system increases. As $T_{\mathrm{g}}$ becomes higher than the cure temperature, the polymer network goes into the glassy state and the diffusion of monomer molecules in the polymer decreases sharply and leads the propagation of curing to be diffusion controlled.
Studies of the gel effect and the kinetics of free-radical polymerization have been reported by several researchers ${ }^{6-8}$ and reviewed by Horie et al. ${ }^{8}$ The onset of autoacceleration or gel effect in free-radical bulk polymerization was related to the model of molecular close packing of random coils by Turner. ${ }^{6}$ Turner proposed that the onset of the gel effect corresponds to close packing of macromolecules with unperturbed dimensions $(\beta=0.5)$. It was suggested that gelation corresponded to the crossover from dilute to the semidilute region and the polymers changed the diffusion behavior into the reptant mode in semidilute solution.

Recent reports ${ }^{9,10}$ of dynamic light scattering (DLS) from polymer semidilute solutions (i.e., polymer concentration is higher than the overlap concentration $C^{*}$ but lower than $50 \mathrm{wt} \%$ ) showed that there were two decay modes. The fast decay mode corresponded to the motion of chain segments between adjacent entanglements whilst the slow mode corresponded to the viscoelastic structure relaxation of the whole molecule. The DLS results revealed that the fast mode decay time was related to the chain length between adjacent entanglements and was polymer molecular weight independent whilst the slow mode decay time was polymer molecular weight dependent. These behaviors were consistent with the scaling theory developed by Brochard and de Gennes. ${ }^{11}$ The termination is related to the motion of polymer radicals. Marten and Hamielec ${ }^{7}$ assumed that the termination reaction becomes diffusion controlled when the diffusion coefficient for a polymer radical $D_{\mathrm{p}}$ becomes less than or equal to a critical diffusion coefficient $D_{\mathrm{pcrt}}$. According to Bueche ${ }^{12}$ the diffusion coefficient of a polymer in entanglement solutions can be related to the free volume fraction and polymer molecular weight. It is also assumed that chain entanglements occur soon after the rate of termination $\left(k_{t}\right)$ becomes diffusion controlled, according to Marten and Hamielec ${ }^{7}$ : 


$$
k_{\mathrm{t}}=k_{\mathrm{to}}\left(\frac{M_{w \mathrm{crt}}}{M_{w}}\right)^{1.75} \exp \left[-A\left(\frac{1}{V_{\mathrm{f}}}-\frac{1}{V_{\mathrm{fcrt}}}\right)\right]
$$

(for linear polymerization with $\alpha>\alpha_{\text {crt }}$ )

where $k_{\mathrm{t} 0}$ is the termination rate constant while conversion $\alpha$ below critical conversion $\alpha_{\mathrm{crt}} ; M_{w \mathrm{crt}}$ the polymer molecular weight at critical point; $V_{\mathrm{f}}$ the free volume fraction; $V_{\mathrm{fcrt}}$ the free volume fraction at critical point; and $A$ a constant. In eq 1 , the $M_{w}$ term corresponds to the motion of whole polymer molecule, and $v_{\mathrm{f}}$ refers to the polymer segments. ${ }^{12}$

Recent reports of DLS from gelatin gel ${ }^{13}$ and poly(vinyl alcohol) gel ${ }^{14}$ showed that only single decay process (fast mode decay) was observed which was identified with the motion of polymer segments between adjacent crosslinks. The slow decay mode corresponding to the polymer viscoelastic structure relaxation was not observed in gels. These results indicated that in polymer gels the motion of segments between adjacent crosslinks was much faster than that of whole polymer molecule which had infinite molecular weight. For crosslinked unsaturated polyester/styrene system there is a critical conversion $\alpha_{\text {crt }}$ and at conversion $\alpha>\alpha_{\text {crt }}$, the polymer is a crosslinked network with an infinite molecular weight and the diffusion coefficient of polymer is related to free volume but not to polymer molecular weight. Hence, eq 1 can be rewritten as:

$$
k_{\mathrm{t}}=k_{\mathrm{t} 0} \exp \left[-A\left(\frac{1}{V_{\mathrm{f}}}-\frac{1}{V_{\mathrm{fcrt}}}\right)\right]
$$

(for crosslinked polymerization with $\alpha>\alpha_{\text {crt }}$ )

In eq 2 only the term concerning the segment motion, i.e., $v_{\mathrm{f}}$, is kept.

During curing $T_{\mathrm{g}}$ of the system increases with the extent of reaction. As curing temperature $T_{\text {cure }}>T_{\mathrm{g}}$, the free volume fraction of the curing system can be written as ${ }^{15}$ :

$$
V_{\mathrm{f}}=V_{\mathrm{fg}}+\beta_{1}\left(T_{\text {cure }}-T_{\mathrm{g}}\right)
$$

where $V_{\mathrm{fg}}$ is assumed to be 0.025 which is the free volume fraction at $T_{\mathrm{g}}$ for most of polymers; and $\beta_{1}$ the thermal expansion coefficient at liquid state. Substituting eq 3 into eq 2 for an isothermal curing reaction, we obtain:

$$
\begin{aligned}
k_{t} & =k_{\mathrm{t} 0} \exp \left[-A\left(\frac{1}{V_{\mathrm{fg}}+\beta_{1}\left(T_{\text {cure }}-T_{\mathrm{g}}\right)}-\frac{1}{V_{\text {fcrt }}}\right)\right] \\
& =k_{\mathrm{t} 0} F_{1}\left(T_{\text {cure }}-T_{\mathrm{g}}\right) \quad\left(\text { for } \alpha_{\text {vit }}>\alpha>\alpha_{\mathrm{crt}}\right)
\end{aligned}
$$

where

$$
\begin{aligned}
& F_{1}\left(T_{\text {cure }}-T_{\mathrm{g}}\right) \\
& \quad=\exp \left[-A\left(\frac{1}{V_{\mathrm{fg}}+\beta_{1}\left(T_{\text {cure }}-T_{\mathrm{g}}\right)}-\frac{1}{V_{\text {fcrt }}}\right)\right]
\end{aligned}
$$

and $\alpha_{\mathrm{vit}}$ is the critical conversion at which $T_{\mathrm{g}}$ of the curing system equals to the curing temperature $T_{\text {cure }}$.

As free radical polymerization proceeds, $T_{\mathrm{g}}$ of the curing system increases. While $T_{\mathrm{g}}$ becomes higher than curing temperature, the curing system vitrified and the propagation of curing reaction becomes diffusion controlled. For a curing reaction with $T_{\text {cure }}<T_{\mathrm{g}}, V_{\mathrm{f}}$ can be expressed as ${ }^{15}$ :

$$
V_{\mathrm{f}}=V_{\mathrm{fg}}+\beta_{\mathrm{g}}\left(T_{\text {cure }}-T_{\mathrm{g}}\right)
$$

where $\beta_{\mathrm{g}}$ is the thermal expansion coefficient at glassy state.

Substituting eq 6 into eq 2, we obtain:

$$
\begin{aligned}
k_{\mathrm{t}} & =k_{\mathrm{t} 0} \exp \left[-A\left(\frac{1}{V_{\mathrm{fg}}+\beta_{\mathrm{g}}\left(T_{\text {cure }}-T_{\mathrm{g}}\right)}-\frac{1}{V_{\text {fcrt }}}\right)\right] \\
& =k_{\mathrm{t} 0} F_{1}^{\prime}\left(T_{\text {cure }}-T_{\mathrm{g}}\right) \quad\left(\text { for } \alpha>\alpha_{\text {vit }}\right)
\end{aligned}
$$

where

$$
\begin{aligned}
& F_{1}^{\prime}\left(T_{\text {cure }}-T_{\mathrm{g}}\right) \\
& \quad=\exp \left[-A\left(\frac{1}{V_{\mathrm{fg}}+\beta_{\mathrm{g}}\left(T_{\text {cure }}-T_{\mathrm{g}}\right)}-\frac{1}{V_{\text {fcrt }}}\right)\right]
\end{aligned}
$$

The diffusion coefficient of a small molecule in a polymer solution can also be related to the free volume fraction $^{12}$ According to Marten and Hamielec, ${ }^{7}$ the propagation rate constant $\left(k_{\mathrm{p}}\right)$ is given by the following expression beyond the vitrification conversion:

$$
k_{\mathrm{p}}=k_{\mathrm{p} 0} \exp \left[-B\left(\frac{1}{V_{\mathrm{f}}}-\frac{1}{V_{\mathrm{fvit}}}\right)\right]
$$

where $B$ is a constant; $k_{\mathrm{p} 0}$ the propagation rate constant while conversion $\alpha \leq \alpha_{\text {vit }}$; and $V_{\text {fvit }}$ the free volume fraction at vitrification. Substituting eq 6 into eq 7, we obtain eq 8 :

$$
\begin{aligned}
k_{\mathrm{p}} & =k_{\mathrm{p} 0} \exp \left[-B\left(\frac{1}{V_{\text {fg }}+\beta_{\mathrm{g}}\left(T_{\text {cure }}-T_{\mathrm{g}}\right)}-\frac{1}{V_{\text {fvit }}}\right)\right] \\
& =k_{\mathrm{p} 0} F_{2}\left(T_{\text {cure }}-T_{\mathrm{g}}\right) \quad\left(\text { for } \alpha>\alpha_{\text {vit }}\right)
\end{aligned}
$$

where

$$
\begin{aligned}
& F_{2}\left(T_{\text {cure }}-T_{\mathrm{g}}\right) \\
& \quad=\exp \left[-B\left(\frac{1}{V_{\mathrm{fg}}+\beta_{\mathrm{g}}\left(T_{\text {cure }}-T_{\mathrm{g}}\right)}-\frac{1}{V_{\text {fvit }}}\right)\right]
\end{aligned}
$$

If $k_{\mathrm{t}}$ and $k_{\mathrm{p}}$ given by eq $4-\mathrm{a}, 4-\mathrm{b}$, and 8 are inserted in the classic rate expression for an isothermal polymerization, one obtains:

Interval $1\left(\alpha<\alpha_{\text {crt }}\right)$

$$
\frac{\mathrm{d} \alpha}{\mathrm{d} t}=\left(f k_{\mathrm{d}}\left[\mathrm{I}_{0}\right]\right)^{1 / 2}(1-\alpha)\left(\frac{k_{\mathrm{p} 0}^{2}}{k_{\mathrm{t} 0}}\right)^{1 / 2}
$$

Interval $2\left(\alpha_{\mathrm{crt}}<\alpha<\alpha_{\mathrm{vit}}\right)$ :

$$
\frac{\mathrm{d} \alpha}{\mathrm{d} t}=\left(f k_{\mathrm{d}}\left[\mathrm{I}_{0}\right]\right)^{1 / 2}(1-\alpha)\left(\frac{k_{\mathrm{p} 0}^{2}}{k_{\mathrm{t} 0}}\right)^{1 / 2}\left(F_{1}\left(T_{\text {cure }}-T_{\mathrm{g}}\right)\right)^{1 / 2}
$$

Interval $3\left(\alpha_{\mathrm{vit}}<\alpha\right)$ :

$$
\begin{aligned}
& \frac{\mathrm{d} \alpha}{\mathrm{d} t}=\left(f k_{\mathrm{d}}\left[\mathrm{I}_{0}\right]\right)^{1 / 2}(1-\alpha)\left(\frac{k_{\mathrm{p} 0}^{2}}{k_{\mathrm{t} 0}}\right)^{1 / 2} \\
& \quad \times\left(F_{1}^{\prime}\left(T_{\text {cure }}-T_{\mathrm{g}}\right)\right)^{1 / 2}\left(F_{2}\left(T_{\text {cure }}-T_{\mathrm{g}}\right)\right)
\end{aligned}
$$

With an assumption $V_{\text {fvit }}=0.025$ ( $V_{\mathrm{f}}$ at cure temperature $\left.T_{\text {cure }}=T_{\mathrm{g}}\right) ; f$ the initiator efficiency; $k_{\mathrm{d}}$ the initiator decomposition rate constant; $\left[\mathrm{I}_{\mathrm{o}}\right]$ the initial initiator concentration; $\alpha$ the degree of conversion; and $t$ the reaction time. 
In this paper, we showed that time-temperaturetransformation of $T_{\mathrm{g}} \mathrm{vs} . \ln \left(t_{\text {cure }}-t_{Z}\right)$ (where $t_{\text {cure }}$ is the curing time, and $t_{Z}$ the induction time for initiator to consume inhibitor) of unsaturated polyester/styrene at different cure temperatures formed a master curve between critical point and vitrification at an arbitrary reference temperature and yielded a single Arrhenius activation energy. The experimental results suggested that for an isothermal curing reaction there existed a critical point such that between critical point and vitrification the curing reactin depended on $T_{\mathrm{g}}$ only.

\section{EXPERIMENTAL}

\section{Unsaturated Polyester}

Unsaturated polyester was polymerized from isophthalic acid (IPA), fumaric acid (FA), and propylene glycol (PG) by the usual condensation method. The mole ratio of the final composition of the polyester resin determined by $\mathrm{NMR}$ was IPA/FA/PG $=1 / 1.64 / 3.23$. Thus, the final unsaturated polyester has the following specifications: the acid value was about $28 \mathrm{mg} \mathrm{KOH} \mathrm{g}^{-1}$, $M_{n}=1800, M_{w}=4300$, and the average unsaturated group per polyester chain is about 6.0. The resin with a styrene/polyester weight ratio of $33 / 67$ and a styrene/FA ratio of 1.43 was used for the DSC curing study.

\section{Initiator}

The peroxide initiator was tert-butyl peroxybezoate from Akzo Chemie Co. with a purity of $98 \%$ and an active oxygen content of $8.0 \%$. In this study, $1 \%$ by weight of initiator was added into the resin.

\section{Differential Scanning Calorimetry (DSC)}

A du Pont 910 DSC was used to measure the exothermic reaction of curing. Hermetic DSC pans were used to minimize losses of volatile materials (such as styrene monomer) during the heating of the sample in the DSC cell. The weight of the sample used ranges from $4 \mathrm{mg}$ to $6 \mathrm{mg}$. A small sample was required in order to achieve isothermal operating during cure. In the use of DSC for studying the isothermal curing kinetics of thermoseting resins, one assumes that the amount of heat generated due to the curing reaction is directly proportional to the degree of curing $\alpha$ (or the extent of reaction) of the sample at that curing time. The detail data treatment to calculate conversion $\alpha$ from DSC data was described elsewhere. ${ }^{5}$

\section{RESULTS AND DISCUSSION}

Unsaturated polyester is a condensation copolymer of saturated diol, saturated dibasic acid, and unsaturated dibasic acid, and the copolymer is crosslinked with styrene monomer. It is known that the curing reaction started only after all of the inhibitors were consumed by initiator. ${ }^{16}$ The time for the initiator to consume inhibitor is the so called "induction time" (i.e., $t_{Z}$ ). The $t_{Z}$ for an isothermal curing reaction can be obtained from an isothermal DSC scan and it is the period from the time at which the sample cell reach curing temperature to the time where curing reaction starts (i.e., the onset of the curing rate $\mathrm{d} \alpha / \mathrm{d} t>0)$. Since the free radical polymeriza-

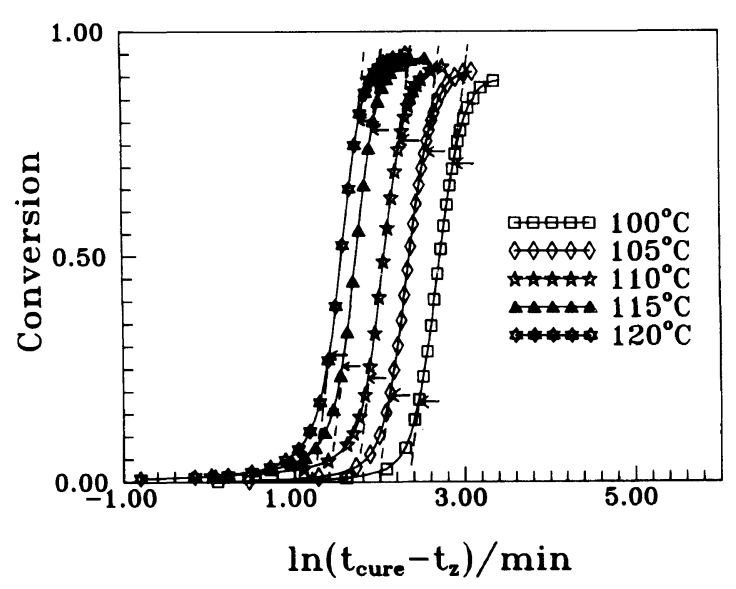

Figure 1. Conversion $\alpha v s \cdot \ln \left(t_{\text {cure }}-t_{\mathrm{Z}}\right)$ for unsaturated polyester/ styrene at various curing temperatures obtained from DSC measurement. The critical point and vitrification points are designated by arrows.

Table I. The induction time, shift factor, and conversions at critical point and vitrification ${ }^{a}$

\begin{tabular}{crcccc}
\hline Cure temp $/{ }^{\circ} \mathrm{C}$ & $t_{\mathrm{z}} / \min$ & $A(T)$ & $\alpha_{\mathrm{crt}}$ & $\alpha_{\text {vit }}$ & $\alpha_{\text {vit }}{ }^{*}$ \\
\hline 100 & 27.9 & Reference & 0.183 & 0.715 & 0.725 \\
105 & 14.7 & 0.359 & 0.196 & 0.738 & 0.750 \\
110 & 7.5 & 0.661 & 0.231 & 0.758 & 0.774 \\
115 & 3.0 & 0.992 & 0.260 & 0.786 & 0.798 \\
120 & 0.3 & 1.165 & 0.277 & 0.806 & 0.822
\end{tabular}

${ }^{a} \alpha_{\mathrm{crt}}$ and $\alpha_{\mathrm{vit}}$ obtained from Figure 3 and designated by arrows in Figure 1. $\alpha_{\mathrm{vit}}{ }^{*}$ calculated from eq 11 .

tion proceeds only after induction period, all of the curing profiles in this work were plotted against $\left(t_{\text {cure }}-t_{Z}\right)$ rather than $t_{\text {cure }}$ (where $t_{\text {cure }}$ is curing time). Figure 1 shows the conversion $\alpha v s . \ln \left(t_{\text {cure }}-t_{Z}\right)$ obtained from DSC measurements for unsaturated polyester resin cured at temperatures $100^{\circ} \mathrm{C}, 105^{\circ} \mathrm{C}, 110^{\circ} \mathrm{C}, 115^{\circ} \mathrm{C}$, and $120^{\circ} \mathrm{C}$. The values of $t_{Z}$ for each curing temperature are listed in Table I.

The theoretical work of $T_{\mathrm{g}}$ for crosslinked polymers has been reported by several workers. ${ }^{17-19}$ The $T_{\mathrm{g}}$ of unsaturated polyester/styrene increases with the extent of curing reaction. Ma et al. ${ }^{20}$ had reported that $T_{\mathrm{g}}$ of the partially cured resins can be related to conversion $\alpha$ by eq 11:

$$
T_{\mathrm{g}}=K_{1} \exp \left(K_{3} \alpha\right)
$$

where $K_{1}$ and $K_{3}$ are constants. In an earlier work, ${ }^{20}$ Ma et al. studied the curing reaction of unsaturated polyester/styrene and reported that $K_{1}$ and $K_{3}$ were $252.0 \mathrm{~K}$ and 0.54 respectively for the same resin used in the present paper. The variations of $T_{\mathrm{g}}$ for the same curing resins as shown in Figure 1 were calculated from eq 11 and are shown in Figure 2.

From eq 10, we know that the curing reaction for $\alpha>\alpha_{\text {crt }}$ is $T_{\text {cure }}-T_{\mathrm{g}}$ dependent. The variation of $\left(T_{\text {cure }}-T_{\mathrm{g}}\right)$ for $\alpha_{\mathrm{vit}}>\alpha>\alpha_{\text {crt }}$ can be described mathematically by the usual kinetic rate equation:

$$
\begin{gathered}
\frac{1}{\left(f\left[\mathrm{I}_{0}\right]\right)^{1 / 2}(1-\alpha)} \frac{\mathrm{d} \alpha}{\mathrm{d} t}=k\left(T_{\text {cure }}\right)\left(F_{1}\left(T_{\text {cure }}-T_{\mathrm{g}}\right)\right)^{1 / 2} \\
\left(\text { for } \alpha_{\text {vit }}>\alpha>\alpha_{\text {crt }}\right)
\end{gathered}
$$




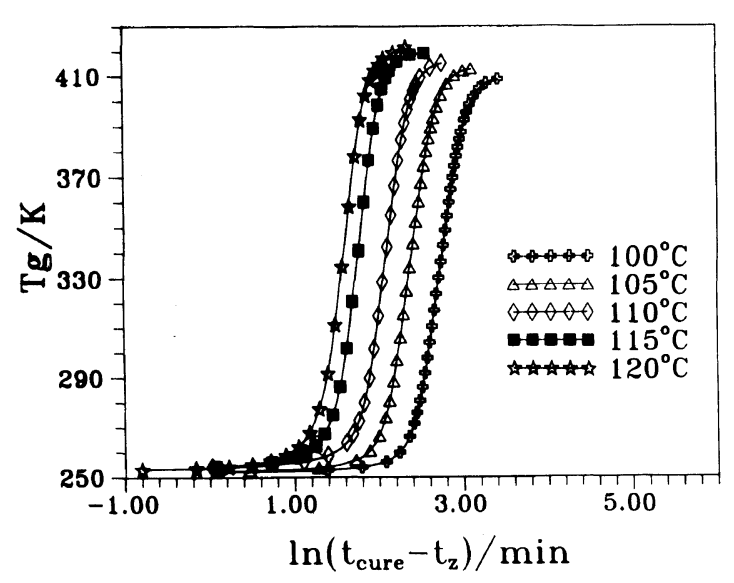

Figure 2. Variations of $T_{\mathrm{g}} v s . \ln \left(t_{\text {cure }}-t_{\mathrm{Z}}\right)$ for unsaturated/styrene at various curing temperatures.

and

$$
k\left(T_{\text {cure }}\right)=k_{\mathrm{p} 0} \frac{k_{\mathrm{d}}^{1 / 2}}{k_{\mathrm{t} 0}^{1 / 2}}
$$

where $k\left(T_{\text {cure }}\right)$ is the reaction rate constant that is a function of curing temperature, $F\left(T_{\text {cure }}-T_{\mathrm{g}}\right)$ is a function of $T_{\text {cure }}-T_{\mathrm{g}}$. At an isothermal curing reaction the right hand side of eq 12 is a function of $T_{\mathrm{g}}$ only. Hence, eq 12 can be rewritten as:

$$
\frac{\mathrm{d} T_{\mathrm{g}}}{\mathrm{d} t}=k\left(T_{\text {cure }}\right) F\left(T_{\mathrm{g}}\right)
$$

(for isothermal curing with $\alpha_{\mathrm{vit}}>\alpha>\alpha_{\mathrm{crt}}$ )

Rearranging eq 14 , at a constant temperature integrating from $t_{Z}$ to any cure time, $t_{\text {cure }}$, between critical point and vitrification, and taking the natural logarithm, we obtain:

$$
-\ln \left(\int_{T_{\mathrm{g}}\left(t_{\text {cure }}=t_{\mathrm{z}}\right)}^{T_{\mathrm{g}}\left(t_{\text {cure }}\right)} \frac{\mathrm{d} T_{\mathrm{g}}}{F\left(T_{\mathrm{g}}\right)}\right)=\ln k\left(T_{\text {cure }}\right)+\ln \left(t_{\text {cure }}-t_{Z}\right)
$$

$$
\text { with } t_{\text {crt }}<t_{\text {cure }}<t_{\text {vit }}
$$

For $\alpha_{\mathrm{vit}}>\alpha>\alpha_{\mathrm{crt}}$, the left hand side of the above eq 14 is a function of $T_{\mathrm{g}}$ only. Therefore,

$$
\boldsymbol{F}\left(T_{\mathrm{g}}\right)=\ln k\left(T_{\text {cure }}\right)+\ln \left(t_{\text {cure }}-t_{\mathrm{Z}}\right)
$$

This equation describes the variation of $T_{\mathrm{g}}$ with cure time and temperature for $\alpha_{\mathrm{vit}}>\alpha>\alpha_{\mathrm{crt}}$. Let $T_{\mathrm{g}}$ vary with time $t_{\text {cure } 1}$ for cure temperature $T_{\text {cure } 1}$, and with time $t_{\text {cure } 2}$ for cure temperature $T_{\text {cure2 }}$ :

$$
\begin{gathered}
\boldsymbol{F}\left(T_{\mathrm{g}}\right)=\ln k\left(T_{\text {cure } 1}\right)+\ln \left(t_{\text {cure } 1}-t_{Z 1}\right) \\
=\ln k\left(T_{\text {cure } 2}\right)+\ln \left(t_{\text {cure } 2}-t_{Z 2}\right) \\
\ln \left(t_{\text {cure } 1}-t_{Z 1}\right)-\ln \left(t_{\text {cure } 2}-t_{Z 2}\right) \\
=\ln k\left(T_{\text {cure } 2}\right)-\ln k\left(T_{\text {cure } 1}\right)
\end{gathered}
$$

For any two isothermal curing temperatures, $\left[\ln k\left(T_{\text {cure } 2}\right)\right.$ $\left.-\ln k\left(T_{\text {cure }}\right)\right]$ is a constant. For the curing reaction between critical point and vitrification, the variation of $T_{\mathrm{g}}$ with cure time at two different cure temperatures ( $T_{\text {cure } 1}$ and $\left.T_{\text {cure } 2}\right)$ when plotted as functions of $\ln \left(t_{\text {cure }}-t_{Z}\right)$ will have the same functional form except

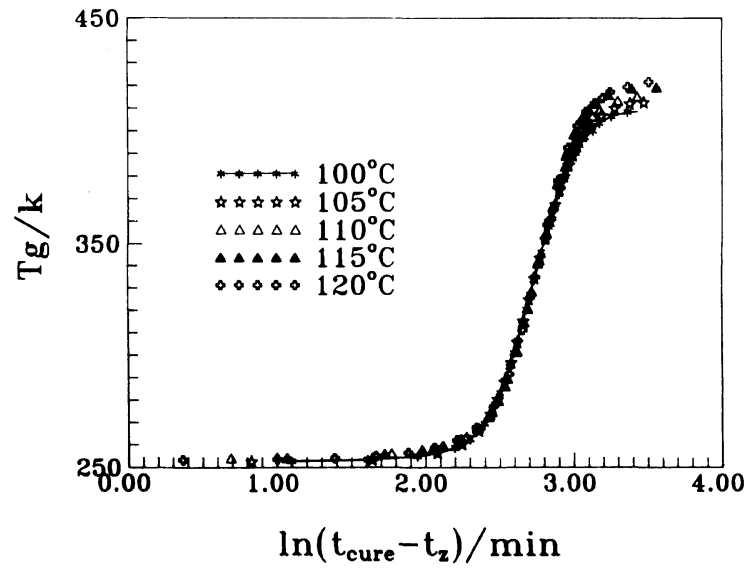

Figure 3. Superposition of $T_{\mathrm{g}} v s \cdot \ln \left(t_{\text {cure }}-t_{Z}\right)$ to form a master curve at $100^{\circ} \mathrm{C}$ by shifting each conversion curve by a constant factor $A\left(T_{\text {cure }}\right)$.

that the curve for $T_{\text {cure2 }}$ will be displaced from that of $T_{\text {cure } 1}$ by a constant factor. It follows that if the curing reaction between critical point and vitrification is $T_{\mathrm{g}}$ dependent only, all $T_{\mathrm{g}} v s \cdot \ln \left(t_{\text {cure }}-t_{\mathrm{Z}}\right)$ curves at different cure temperatures should be superposable between critical point and vitrification by simply shifting each curve along the $\ln \left(t_{\text {cure }}-t_{z}\right)$ axis relative to a curve at an arbitrary reference temperature by a shift factor, $\left.A\left(T_{\text {cure }}\right)=\ln \left(t_{\text {cure }}-t_{Z}\right)_{T_{\text {ref }}}-\ln \left(t_{\text {cure }}-t_{Z}\right)_{T_{\text {cure }}}\right]$, for each temperature relative to the reference temperature. The variations of $T_{\mathrm{g}}$ vs. $\ln \left(t_{\text {cure }}-t_{\mathrm{Z}}\right)$ curves of unsaturated polyester/styrene system cured at different temperatures are shifted along the $\ln \left(t_{\text {cure }}-t_{z}\right)$ axis and are shown in Figure 3. So that the portion for $\alpha_{\mathrm{vit}}>\alpha>\alpha_{\mathrm{crt}}$ of each curve coincides with that of the curve at $T_{\text {ref }}=100^{\circ} \mathrm{C}$ and form a master curve at $100^{\circ} \mathrm{C}$. The shift factors, $A\left(T_{\text {cure }}\right)$, used in shifting the curves relative to $T_{\text {cure }}=100^{\circ} \mathrm{C}$ are summarized in Table I. These results were similar to the data of the curing reaction of trimethylene glycol di-p-aminobenzoate (TMAB)/diglycidyl ether of bisphenol A (DGEBA) reported by Gillham and coworker. ${ }^{3}$ Time-temperature shifts of $T_{\mathrm{g}} v s . \ln$ (cure time) data of the curing profiles of TMAB/DGEBA at different cure temperatures to form a master curve before vitrificatin at an arbitrary reference temperature yield a single Arrhenius activation energy $\left(63.8 \mathrm{~kJ} \mathrm{~mol}^{-1}\right)$.

It can be seen from Figure 3 that $T_{\mathrm{g}}$ data between critical point and vitrification for all cure temperatures can be superimposed to form a master curve. The $T_{\mathrm{g}}$ data branched off from the master curve for $\alpha<\alpha_{\text {crt }}$ and $\alpha>\alpha_{\mathrm{vit}}$ as designated by arrows in Figure 1. The values of $\alpha_{\text {crt }}$ and $\alpha_{\text {vit }}$ obtained from plots for various curing temperatures are also listed in Table I. Because of the influence of the kinetic control termination reaction and polymer molecular weight dependent termination reaction, $T_{\mathbf{g}}$ profiles branch off from the master curve before critical point; whilst the diffusion controlled propagation leaded the $T_{\mathrm{g}}$ profile to branch off from the master curve after vitrification.

To observe the vitrification effect in the curing reaction, the vitrification conversion $\alpha_{\mathrm{vit}}$ at which the curing temperature, $T_{\text {cure }}$, equals to $T_{\mathrm{g}}$ was calculated from eq 11 for various curing temperatures and the results are shown in Table I. From Table I, we know that the values 


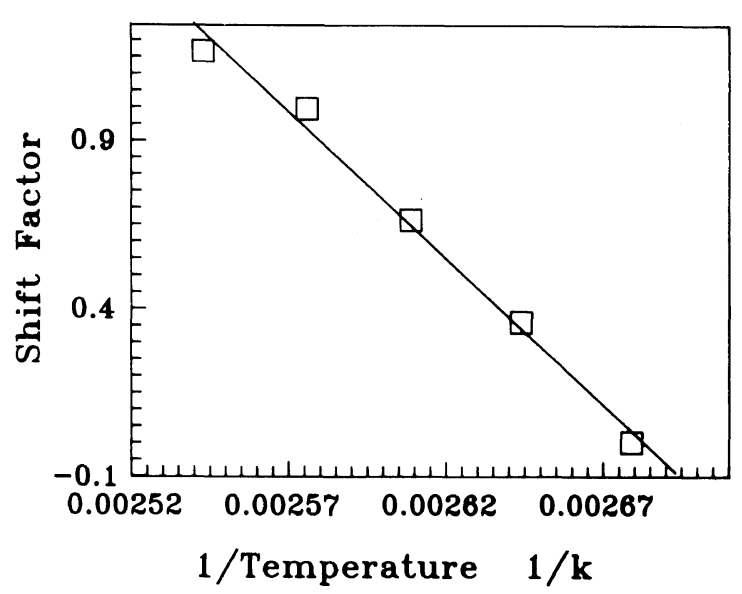

Figure 4. Arrhenius plot of the shift factors, $A\left(T_{\text {cure }}\right)$, vs. $1 / T_{\text {cure }}$

of $\alpha_{\text {vit }}$ obtained from plots (i.e., Figure 3) are very close to those calculated from eq 11 . This results revealed that the propagation of curing reaction becomes diffusion controlled as $T_{\mathrm{g}}$ of curing system being higher than $T_{\text {cure }}$.

For a steady state free radical polymerization, the temperature dependence of the rate constant is generally given by an Arrhenius relationship ${ }^{16}$ :

$$
\begin{aligned}
& k(T)=A_{0} \exp (-E / R T) \\
& \quad=\frac{A_{\mathrm{d}}^{1 / 2} A_{\mathrm{p}}^{0}}{A_{\mathrm{t}}^{1 / 2}} \exp \left[\frac{\left.-E_{\mathrm{d}}+2 E_{\mathrm{p}}-E_{\mathrm{t}}\right) / 2}{R T}\right]
\end{aligned}
$$

where $E$ is the activation energy, $R$ the gas constant, and $A_{0}$ an Arrhenius constant. The shift factors listed in Table I can be used to calculate the Arrhenius activation energy for the polymerizatin, since eq 19 provides the relationship between the time shift factors and the rate constants:

$$
\begin{aligned}
& A\left(T_{\text {cure }}\right)=\ln \left(t_{\text {cure }}-t_{Z}\right)_{T_{\text {ref }}}-\ln \left(t_{\text {cure }}-t_{Z}\right)_{T_{\text {cure }}} \\
& \quad=\ln k\left(T_{\text {cure }}\right)-\ln k\left(T_{\text {ref }}\right)=-\frac{E}{R T_{\text {cure }}}+\frac{E}{R T_{\text {ref }}}
\end{aligned}
$$

When $T_{\text {ref }}$ is fixed and all other data are shifted relative to the reference temperature (for the present case $\left.T_{\text {ref }}=100^{\circ} \mathrm{C}\right)$, plotting the shift factor $\left[\ln \left(t_{\text {cure }}-t_{Z}\right)_{T_{\text {ref }}}-\right.$ $\ln \left(t_{\text {cure }}-t_{Z}\right)_{T_{\text {cure }}}$ ] against $1 / T$ should yield a straight line with slope given by $-E / R$ and intercept equal to $E / R T_{\text {ref }}$. The shift factors in Table I are plotted against $1 / T_{\text {cure }}$ and shown in Figure 4. The resulting plot is a straight line, the slope of which yields an activation energy for the curing reaction of $72.5 \mathrm{~kJ} \mathrm{~mol}^{-1}$. The value of activation energy was in consistent with that of typical free radical polymerization. (The values of $E_{\mathrm{p}}, E_{\mathrm{t}}$, and $E_{\mathrm{d}}$ for free radical polymerization of styrene with peroxybenzoate initiator are $26 \mathrm{~kJ} \mathrm{~mol}^{-1}, 8.0 \mathrm{~kJ} \mathrm{~mol}^{-1}$, and $134 \mathrm{~kJ} \mathrm{~mol}^{-1}$ respectively. ${ }^{16}$ Thus, the activation energy for the polymerization of styrene is $E=E_{\mathrm{d}} / 2+$ $\left.E_{\mathrm{p}}-E_{\mathrm{t}} / 2=89 \mathrm{~kJ} \mathrm{~mol}^{-1}\right)$. These results suggest that between critical point and vitrification there is only one $T_{\mathrm{g}}$ dependent reaction mechanism with a single over all apparent activation energy.

\section{CONCLUSIONS}

Time-temperature shifts of $T_{\mathrm{g}} v s . \ln \left(t_{\text {cure }}-t_{z}\right)$ data for unsaturated polyester/styrene at different cure temperatures form a master curve between critical point and vitrification at an arbitrary temperature and yield a single Arrhenius activation energy. The results revealed that progress of curing reaction for conversion $\alpha_{\mathrm{vit}}>\alpha>\alpha_{\mathrm{crt}}$ was a function of $T_{\mathrm{g}}$.

Acknowledgement. The authors would like to acknowledge research support by the National Science Foundation of ROC through grant NSC-82-0405-E-155071.

\section{REFERENCES}

1. R. Burns, "Polyester Molding Compounds," Macel Dekker, New York, N. Y., 1982.

2. G. Lubin, "Handbook of Composites," Van Nostrand Reinhold, New York, N.Y., 1982.

3. G. Wisanrakkit and J. K. Gillham, J. Appl. Polym. Sci., 41, 2885 (1990).

4. Y. S. Yang and L. J. Lee, Polymer, 29, 1793 (1988).

5. S. B. Liu, L. J. Liu, and T. L. Yu, J. Appl. Polym. Sci., 53, 1165 (1994).

6. D. T. Turner, Macromolecules, 10, 221 (1977).

7. F. L. Marten and A. E. Hamielec, J. Appl. Polym. Sci., 27, 489 (1982).

8. I. Mita and K. Horie, J. Macromol. Sci.-Rev. Macromol. Chem. Phys., C27, 91 (1987).

9. M. Adam and M. Delsanti, Macromolecules, 18, 1760 (1985).

10. T. Nicolai, W. Brown, R. M. Johnsen, and P. Stepanek, Macromolecules, 23, 1165 (1990).

11. F. Brochard and P. G. deGennes, Macromolecules, 10, 1157 (1977).

12. F. Bueche, "Physical Properties of Polymers, Interscience," New York, N. Y., 1962.

13. E. J. Amis, P. A. Janmey, J. D. Ferry, and H. Yu, Macromolecules, 16, 441 (1983)

14. L. Fang and W. Brown, Macromolecules, 23, 3284 (1990).

15. J. D. Ferry, "Viscoelastic Properties of Polymers," 3rd ed, John Wiley \& Sons, New York, N. Y., 1980.

16. G. Odian, "Principles of Polymerization," 3rd ed, John Wiley \& Sons, New York, N. Y., 1991.

17. L. E. Nielson, J. Macromol. Sci. Rev. Macromol. Chem., C3, 69 (1969).

18. H. Stutz, H.-H. Illers, and J. Mertes, J. Polym. Sci., Polym. Phys. $E d ., 28,1483$ (1990).

19. S. C. Ma and T. L. Yu, J. Polym. Eng., 12, 179 (1993).

20. S. C. Ma, H. L. Lin, and T. L. Yu, Polym. J., 25, 897 (1993). 